\title{
The Study of the Formation of Students' Competence in Intercultural Communication in the Digital Educational Environment
}

\author{
Alexander Morozov ${ }^{1, a *}$, Olga Mikhaleva ${ }^{2, b}$ \\ 1 Institute of Education Management of the Russian Academy of Education, 105062, 16 \\ Zhukovsky str., Moscow, Russia \\ 2 Vladimir State University named after A. G. and N. G. Stoletovs, 600000, 87 Gorky str., Vladimir, \\ Russia \\ adoc_morozov@mail.ru, ${ }^{b}$ denisovaolga@inbox.ru \\ ${ }^{*}$ Corresponding author
}

\begin{abstract}
Keywords: competence in the field of intercultural communication, digital educational environment, communicative activity, integral indicator, integrative cultural and professional knowledge; integrative skills

Abstract : The paper focuses on the actual issues of the formation of students' competence in intercultural communication in a digital educational environment. The goal is to confirm or deny the assumption that communicative activity acts as an integral indicator characterizing the level of development of the studied competence. The research uses a multimethod research design and relies on extensive empirical data. Being developed and implemented in practice, a set of measures aimed at building competence in the field of intercultural communication among students of non-linguistic universities in a digital educational environment showed its validity and focus, which allowed to solve the scientific problems of the pedagogical experiment and confirmed the hypothesis.
\end{abstract}

This paper starts an empirical research aimed at studying the process of formation of students of nonlinguistic universities in the field of intercultural communication in a digital educational environment. The goal is to confirm or deny the assumption that communicative activity acts as an integral indicator characterizing the level of development of the studied competence.

Empirical research was carried out in three logically interrelated stages. At the first stage, a recording experiment was conducted. Its goal was to determine the current level of competence formation in the field of intercultural communication in the future Bachelor-linguists. At the second stage, a formative experiment was organized and conducted. The purpose of the formative stage of the experimental study was to test the structural-functional model developed by us for the formation of competences under study during the educational process for students who were included in the experimental group. During the third stage, the control experiment, the effectiveness of the structural-functional model was evaluated by comparing the indicators characterizing the level of formation of students of the control and experimental competence groups in the field of intercultural communication in a digital educational environment.

Experimental work included pilotage and basic empirical research and had the following order of research activities: (i) the use of a set of measurement procedures for determining the system of criteria and indicators characterizing the level of competence formation in the field of intercultural communication among future Bachelor-linguists; (ii) identification of conditions conducive to the process of formation of the studied competence; and (iii) experimental work.

The empirical base of the study was in the Humanitarian Institute of the Vladimir State University named after AG and N.G. Stoletovs. A total of 108 students enrolled in the field of study 45.03.02 ("Linguistics") took part in the study.

Based on the criteria outlined in the framework of the model developed by us, we identified the four levels of formation of competence in the field of intercultural communication among students who are going to be the future Bachelor-linguists in a digital educational environment: reproductive; adaptive; 
heuristic; creative [2].

We also focused on: (i) the levels of competence development indicated above were evaluated by a complex of integrative parameters; (ii) integrative cultural and professional knowledge; (iii) integrative skills; (iv) the degree of development of integrative professionally important features of a person; (v) degree of readiness of integrative professional intentions for future professional activity [8].

During the empirical study, we used the following methods: observation, experiment, conversation, testing, content analysis, expert evaluation method, mathematical and statistical methods of processing results.

Cognitive criterion (cognitive readiness). Determining the indicators of the cognitive criterion in the framework of the ascertaining experiment included measurements on the basis of: determining the average grade point, subject assessment, appropriate courses of study, communicative attribution, and propensity to organize a communicative process.

The locus of control (localization of control) is a characterological feature that gives an idea of a person's tendency to attribute responsibility for the results of his activity to external influences or authentic efforts. The locus of control is a stable property of a person, formed in the process of its development in society, used to diagnose the partial positions of internality and externality of a person, aimed at studying the partial scales of the locus of control [6].

Determining the level of subjective control, we tried to determine the responsibility, tolerance, selfdevelopment, and integrative element, covering all the previous and present in each of them. The level of development of positive thinking and cognition of the surrounding world was also determined [5]. In our opinion, the value of the locus of control is that it acts as one of the defining indicators of a person's social maturity [3].

As part of our study, we analyzed the scale of total internality (It), the scale of internality in the field of achievement (Ia), the scale of internality in the field of failure (If), the scale of internality in the sulfur of interpersonal relations (Ii). The arithmetic average indicators of the personality internality within the framework of the ascertaining experiment are presented in Table 1.

TABLE 1. INDICATORS OF THE INITIAL LEVEL OF INTERNALITY IN THE CONTROL AND EXPERIMENTAL GROUPS (\%).

\begin{tabular}{|l|c|c|c|c|c|c|}
\hline \multirow{2}{*}{$\begin{array}{l}\text { Indicator, } \\
\text { Criterion }\end{array}$} & \multicolumn{3}{|c|}{ Control group } & \multicolumn{3}{c|}{ Experimental group } \\
\cline { 2 - 7 } & Low (\%) & Average (\%) & High (\%) & Low (\%) & Average (\%) & High (\%) \\
\hline Total internality & 20 & 69 & 11 & 19 & 72 & 9 \\
\hline $\begin{array}{l}\text { Internality of } \\
\text { achievements }\end{array}$ & 23 & 68 & 9 & 20 & 72 & 8 \\
\hline Failure internality & 19 & 75 & 6 & 18 & 73 & 9 \\
\hline $\begin{array}{l}\text { Internality of } \\
\text { interpersonal } \\
\text { relations }\end{array}$ & 17 & 76 & 7 & 18 & 74 & 8 \\
\hline
\end{tabular}

One of the indicators of the cognitive criterion is communicative readiness, the method of measurement is "Communicative social competence" (CSC) (A. A. Derkach, A. N. Sukhov). The technique is used to obtain a more complete characterization of the personality, modeling the intended result of the effectiveness of its professionalism in a future profession. This methodology includes the following scales: sociability, analytical, logical mental operations, emotional stability, lightness, sensitivity, autonomy, selfdiagnostics, a tendency to deviate (deviant) behavior. The data obtained as a result of the study give an idea of the severity of one or another factor.

Competence in the field of intercultural communication was measured using the "Communication and organizational propensity" methodology (V. V. Sinyavsky, V. A. Fedoroshin). We used one scale "communicative inclinations". 
The results of diagnostics in the course of the ascertaining experiment showed that the students who entered both the experimental and the control groups had a similar level of communicative inclinations.

Within the framework of the activity criterion (information professionalism, creativity, professional flexibility), indicators were determined, including measurements based on the results of subject diagnostics, qualitative analysis of diary entries and reports on the practice, determining the level of creativity and sociopsychological flexibility (determination of rigidity).

The key competence "creativity" was measured using the method of "individual assessment of creativity" (A.V. Morozov), with the help of which it was possible not only to determine the level of creative abilities of students, but also to construct a psychological creative profile by analyzing various components [4].

Our survey showed that $20 \%$ of students think over options for solving complex problems before choosing the most effective way. $15 \%$ of respondents are afraid to go to a meeting with a stranger because of the fear of not knowing a technology of building constructive dialogue. $17 \%$ of respondents use humor to solve complex problems. $23 \%$ of respondents are trying to think through all the stages of their creative work. $25 \%$ of them periodically lost interest in life.

In order to measure rigidity, we used the "diagnostics of socio-psychological mobility" methodology (E. F. Zeer). The purpose of this test was to determine the levels of expression in terms of mobility and social desirability. The choice of this technique was due to the fact that rigidity is a difficulty, and sometimes a complete inability to change the program of activities planned by a person in conditions that objectively dictate its restructuring.

Analysis of the results obtained after the test, make it possible to conclude that the percentage ratio of mobility and social desirability in both experimental and control groups is about the same. In $30 \%$ of students, life stance is based on a sense of duty; $16 \%$ of them do not keep their promises from time to time; $19 \%$ of the respondents do not like to dive into the problem under investigation; $15 \%$ of them easily agree with the opinion of another person, especially if it is meaningful to them, without going into details; $20 \%$ of the surveyed are trying to achieve their goals.

In order to determine the ability of students to communicate, we applied L. Michelson's communication skills (translation and adaptation by $\mathrm{Yu}$. Z. Gilbukh), used to diagnose the level of communicative awareness and the quality of functioning of the main communication skills. The technique allows to diagnose the following aspects of communication skills: (i) an ability to carry out and make psychological stroking from the opposite; (ii) a reaction to objective criticism; (iii) responses to subjective criticism; (iv) responding to incorrect, tactless behavior on the part of the communication partner; (v) an ability to contact a partner with a request; (vi) an ability to say "no" in response to someone else's request; (vii) an ability to show empathy towards others; (viii) an ability to adequately accept sympathy and help from fellow students; (ix) an ability to enter into dialogue with another person, sociability; (x) a reaction to the desire to communicate with other people.

The personal criterion was focused on determining the level of development of professionally important personal characterological features of the future bachelor-linguist: responsible behavior, reliability, perseverance, empathy, objectivity of personal characteristics and self-criticism.

The definition of these indicators included measurements based on the method of value orientations (M. Rokich), which is based on a direct ranking of the register of values. M. Rokich differentiated two classes of values: (i) terminal ones - argumentation of beliefs, to what final goal of ontogenetic existence it is necessary to strive for; and (ii) instrumental ones, including beliefs, indicating a course of action or character traits of a person, acting as more preferable in any situation.

Interviewing students for the presence of terminal values, we found that $24 \%$ of respondents have common sense, maturity of judgment. $18 \%$ of them had good and loyal friends. $26 \%$ love entertainment as a burdensome pastime. And $32 \%$ of the surveyed want them to have a happy family life.

According to instrumental values, the survey shows the following picture: $31 \%$ are irreconcilable for shortcomings in themselves and others; $16 \%$ have a sense of responsibility; $23 \%$ say that they have a strong will; $29 \%$ of them state that they tolerance. 
Diagnosis of emotional intelligence (N. Hall) involves identifying an ability to analyze the relationship of a person, expressed in emotions, and management of the emotional sphere, taking into account the decision.

A survey of students according to this methodology shows that $27 \%$ are not fixed on negative emotions; $18 \%$ relate to life problems exclusively from a creative position; $26 \%$ are easily disconnected from trouble; $29 \%$ can help other people, building on their potential.

The technique of diagnosing reflexivity (A. V. Karpov, V. V. Ponomarev) is aimed at determining the level of reflexivity, as an important feature of the personality.

Using the method of evaluating reflexivity, we find that $14 \%$ of students are painfully experiencing their failures; $21 \%$ build a preliminary plan, before starting any business; $19 \%$ are worried about their future; $38 \%$ admit to making ill-considered decisions; $8 \%$ rarely regret what was said.

The motivational and value criterion serves as an integrative indicator of the formation of competence in the field of intercultural communication, the definition of which included measurements of the diagnosis of the individual orientation according to the method developed by B. Bass.

Differences in the results of testing according to the methods of "evaluation of reflexivity", "Individual assessment of creativity", "social-psychological mobility", "value orientations", "evaluation of emotional intelligence" in the control and experimental groups were insignificant.

The integral assessment obtained from the results of the ascertaining experiment allows us to conclude that the vast majority of students $(72 \%)$ shows a low level of competence in the field of intercultural communication. Students have not formed an idea about the importance of the future profession, about personal qualities necessary for mastering the skills of intercultural communication. In addition, they are poorly oriented in the problems of intercultural interaction. The average level was found only in $22 \%$ of students who have an approximate judgment about the main problems of their future profession. High level was found in only $6 \%$ of them.

Thus, the ascertaining experiment shows that it is necessary to modify the conceptual core of the scientific and methodological support process that we have developed to form competence in the field of intercultural communication. More than that, it is necessary to implement a structural-functional model of competence formation in students in a digital educational environment.

Further experimental work on the formation of competence in the field of intercultural communication was carried out with the implementation of a structural-functional model that includes the invariant and variable components.

The invariant component included the basic course "Introduction to the theory of intercultural communication" for first-year students. A special component of the special course "Intercultural communication in the professional sphere" for first-year students enrolled in the undergraduate program in Linguistics entered the variable component of the model. The volume of the special course is 36 classroom hours; 72 hours are allotted for independent out-of-class work, in accordance with the requirements of the Federal State Educational Standards of Higher Education. The content of the course includes the following educational modules: "Essential core and basic directions of research on the technology of intercultural communication", "Specificity of constructing a language personality in the process of intercultural communication."

The development of the model was carried out with the help of a selection of efficient technologies used in the special course "Intercultural communication in the professional sphere" and focused on the motivational and need spheres of students and use it in professional activities.

The purpose of organizing all types of activities for students in the framework of the special course "Intercultural communication in the professional sphere" developed by us was a diverse palette of forms and methods used in independent work, differentiated both in the degree of variability and in presentation.

As part of the formative stage of the experiment, our attention was focused on the fundamental role of students mastering a number of heuristic methods: brainstorming method, focal object method, morphological black box method, key question method, synectic method, inversion method, empathy 
method [7; 11], as well as case studies, debriefing, discussion aquarium, digital content analysis, work with digital dictionaries, etc. [10]. The experiment shows that these methods can be extrapolated as effective didactic tools facilitating the formation of competence in the field of intercultural communication among students of non-linguistic universities. The program implemented by us assigns a basic role to the specifics of tutorial actions for the methodological transformation of the restructuring of professional training for future Bachelors.

When designing an experimental program, we focused on a theoretical analysis of aspects of the study that highlighted the specifics of qualification requirements for the Bachelor's level and determined innovative techniques that ensured the development of communication skills in a foreign language environment $[1 ; 9 ; 13]$.

For the formation of knowledge about different cultures in the framework of studying the special course "Intercultural communication in the professional sphere," it is appropriate to design and implement modular technologies. This is due to the fact that, on the one hand, modular technologies are based on the principles of the competence approach, which includes all constructive developments in the personal approach, which implies the activity of students, subject-subject, value-oriented interaction in the implementation of foreign language communication. On the other hand, modular technologies are quite flexible and contain a great potential for individualizing education, because students are activated to choose the tasks that are the most significant and priority for them. In addition, the reputation of students in the educational process is being updated, since every student personally takes considerable responsibility for the final result of the training. Modular technologies contribute to positive learning at the expense of a meaningful field, the disclosure of the individual abilities of the individual, as well as by relying on the life strategy [12].

The form of implementation of this module was the special course "Intercultural communication in the professional sphere". The purpose of the study was intercultural communication in a digital educational environment.

Each type of activity of Bachelors in the framework of the special course "Intercultural communication in the professional sphere" developed by us suggested a diverse palette of tasks for independent work, differentiated both in the degree of variability and in presentation.

The experience of using digital resources in the process of teaching intercultural communication of bachelors showed that they contributed to the students' natural need for communication and shaped their culture (which is necessary in any activity).

Studying the levels of competence formation in the field of intercultural communication, we used the following techniques: "Communicative social competence" (AA Derkach, AN Sukhov), "Communication and organizational tendencies" (V. V. Sinyavsky, V. A. Fedoroshin) and "Evaluation of communicative skills" (L. Michelson).

Comparing the data obtained on the "communicative propensities scale," we found that the arithmetic mean parameters increased during the training of Bachelors on an experimental program. Significant differences were obtained between indicators of the control and experimental groups. This is explained by the nature of the modules of the special course being developed and tested in the experimental group.

The students included in the experimental group are distinguished by a pronounced sociability, openness, logical thinking, sensitivity, a tendency to artistic thinking and self-control, and an ability to obey the rules.

Students included in the control group are distinguished by pragmatism, indifference, emotional lability, coldness.

In the course of the study, we used three (out of four) levels of competence formation in the field of intercultural communication. Since the Bachelor-linguists already have a reproductive level, then the levels for which changes were identified: adaptive, heuristic, and creative (low, medium , and high).

A student, who has a creative level, realizes quite deeply the importance of his profession, not only for himself but also for the whole society. He shows empathy, initiative, independence, tolerance, respect for 
other cultures, consciously owns experiences of intercultural communication, using anthropogenic values, a creative approach to the implementation of any tasks, focused on the completeness and strength of knowledge, careful and independent thinking through the content of extracurricular events in the paradigm of intercultural interactions, possesses characterological features necessary for the organization of an effective intercultural interaction in a multicultural environment. He has a strategy and tactics of verbal behavior, readiness for future professional activities, modeling situations with transformation into the field of future professional activities, knowledge in a foreign language related to future professional activities.

The heuristic level of students is characterized by a sufficient degree of awareness of the importance of their profession both for themselves and for society. The feeling of empathy, initiative, independence, tolerance, respect for other cultures manifest themselves sporadically. Carrying out intercultural communication, the Bachelor does not always rely on man-made values. As a rule, he creatively performs any task, but not always carefully and independently thinks over the content of extracurricular events in the paradigm of intercultural interactions, and does not strive for the completeness and strength of knowledge. These students are not sufficiently fixed and show personal qualities necessary for the organization of effective intercultural interaction in a multicultural environment. The student does not feel the need to independently develop strategies and tactics of verbal behavior. Readiness for future professional activity is initiated by simulating situations by analogy. By searching for information in a foreign language, he can conduct a clear relationship between the material being studied and future professional activity.

Students with an adaptive level lack empathy, initiative, independence, patience, and respect for other cultures. Carrying out intercultural communications, they do not rely on man-made values. As a rule, they perform any tasks for a given algorithm. They do not think over the content of extracurricular activities in the paradigm of intercultural interactions, and do not strive for the depth and fundamental knowledge. They lack the characterological features necessary for organizing successful intercultural interaction in a multicultural environment; they do not have questions related to strategies and tactics of verbal behavior and choose standard situations that allow solving professional tasks in traditional ways. At the level of using information in a foreign language, when trying to explain the relationship of the material being studied with future professional activity, students show a low level of language skills.

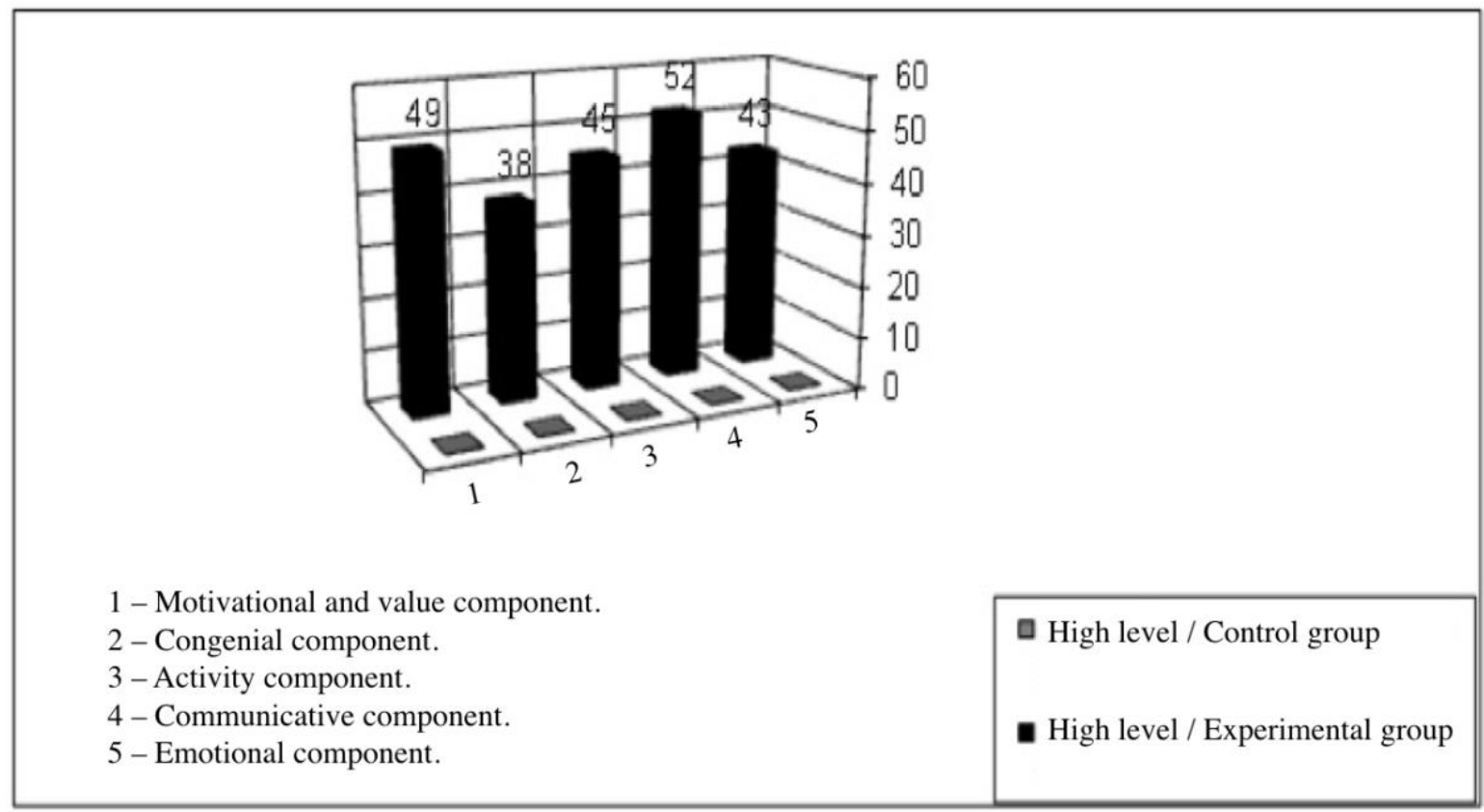

Fig. 1. Indicators of the creative level of competence formation in the field of intercultural communication. 


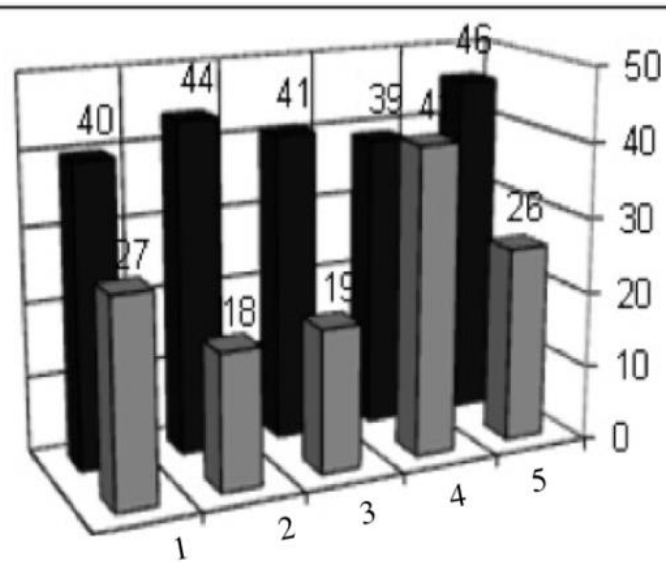

1 - Motivational and value component.

2 - Congenial component.

Medium level / Control group

3 - Activity component.

4 - Communicative component.

5 - Emotional component.

Medium level / Experimental group

Fig. 2. Indicators of the heuristic level of competence formation in the field of intercultural communication.

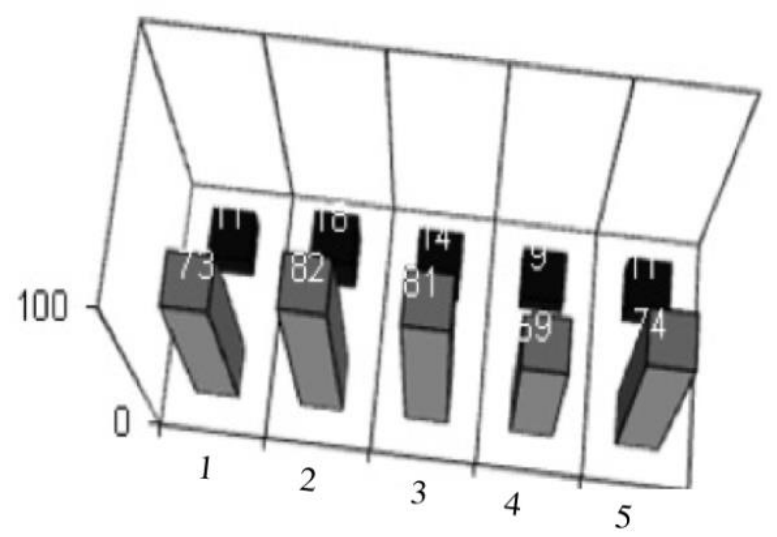

1 - Motivational and value component.

2 - Congenial component.

Low level / Control group

3 - Activity component.

4 - Communicative component.

5 - Emotional component.

Low level /

Experimental group

Fig. 3. Indicators of adaptive level of competence formation in the field of intercultural communication.

Analysis of the results presented graphically in Fig. 1-3 allows us to conclude that after the authors' special course was tested as part of a formative experiment, there were significant changes in the indicators of students in the experimental group regarding the levels of competence in the field of intercultural communication.

Analysis of the results of our pedagogical experiment on the formation of competence among students enrolled in "Linguistics" (undergraduate level) suggests that the adaptive level of formation of competence in the field of intercultural communication reached $22 \%$, heuristic level reached $48 \%$ ( 2 times more than at the beginning of the experiment), and $27 \%$ of the students achieved the creative level, in aggregate - $75 \%$ (most students have reached heuristic and creative levels). 
TABLE 2. RESULTS ON THE LEVEL OF FORMATION OF COMPETENCE IN THE FIELD OF INTERCULTURAL COMMUNICATION AMONG STUDENTS OF EXPERIMENTAL AND CONTROL GROUPS.

\begin{tabular}{|c|c|c|c|c|}
\hline \multirow{2}{*}{ Levels } & \multicolumn{3}{|c|}{$\begin{array}{c}\text { At the beginning of the } \\
\text { experiment, \% }\end{array}$} & \multicolumn{2}{c|}{ At the end of the experiment, \% } \\
& EG & 18 & CG & 11 \\
\hline Reproductive & 13 & 70 & 22 & 43 \\
\hline Adaptive & 65 & 9 & 48 & 34 \\
\hline Heuristic & 17 & 3 & 27 & 12 \\
\hline Creative & 5 & & 3 & \\
\hline
\end{tabular}

Thus, communicative activity acts as an integral indicator characterizing the level of competence formation in students in the field of intercultural communication in a digital educational environment.

Being developed and implemented in practice, a set of measures aimed at building competence in the field of intercultural communication among students of non-linguistic universities in a digital educational environment showed its validity and focus, which allowed to solve the scientific problems of the pedagogical experiment and confirmed the hypothesis.

\section{Acknowledgments}

The article was prepared in the framework of the implementation of the State task of the Ministry of Education and Science of Russia for 2018 on the topic №27.9385.2017/БЧ “Theoretical and methodological foundations of the professional development of education system managers".

\section{References}

[1] Bikiteeva, R. R. (2007). Formation of student intercultural competence: personal-semantic aspect. Orenburg, Russia.

[2] Mikhaleva, O. V. (2017). Structural components of intercultural competence. In Achievements and prospects of science: a collection of scientific articles (pp. 262-265). Ufa, Russia: AETERNA.

[3] Morozov, A. V. (2005). Business psychology. Moscow, Russia: Academic Project.

[4] Morozov, A. V. (2001). Diagnostics of creativity in teaching. Moscow, Russia: IGUMO.

[5] Morozov, A. V. (2002). Communication and thinking. In V. A. Goryanina (Ed.), Psychology of communication (pp. 37-41). Moscow, Russia: Academy.

[6] Morozov, A. V. (2005). Fundamentals of psychology. Moscow, Russia: Academic Project.

[7] Morozov, A. V. (2005). Management psychology. Moscow, Russia: Academic Project.

[8] Morozov, A. V., \& Mikhaleva, O. V. (2017). Prevention of intolerance in the student environment as one of the conditions for resolving intercultural problems. In Formation of civil sustainability as a factor in countering the ideology of extremism and terrorism: Proceedings of the All-Russian Scientific and Practical Conference with international participation (pp. 208-210). Kazan, Russia.

[9] Narolina, V. I. (2010). Psychological Science and Sducation, 2, pp. 1-11. Retrieved from http://psyedu.ru/.

[10] Panina, T. S., \& Vavilova, L. N. (2006). Modern ways to enhance learning. Moscow, Russia: Academy.

[11] Sadykova, A. R. (2011). Bulletin of the Tver State University (Series Pedagogy and Psychology), 1, pp. 90-94. 
[12] Khalupo, O. I. (2012). Philological Sciences: Questions of Theory and Practice, 5(16), pp. 192-195.

[13] Byram, M. (2009). Sprogforum, 6(18), pp. 8-13. 